\title{
Development and applications of solids-free oil-in-water drilling fluids
}

\author{
Yue Qiansheng ${ }^{1,2} *$ and Ma Baoguo ${ }^{1}$ \\ ${ }^{1}$ Key Laboratory of Silicate Materials Science and Engineering, Wuhan University of Technology, Wuhan, Hubei 430070, \\ China \\ ${ }^{2}$ Yangtze University, Jingzhou, Hubei 434023, China
}

\begin{abstract}
The increasing application of near balanced drilling technology to low-pressure and depleted fractured reservoirs requires the use of low-density drilling fluids to avoid formation damage. Solidsfree oil-in-water $(\mathrm{O} / \mathrm{W})$ emulsion drilling fluid is one type of low-density drilling fluid suitable for depleted fractured reservoirs. In this paper, the solids-free $\mathrm{O} / \mathrm{W}$ drilling fluid was developed and has been successfully used in the Bozhong 28-1 oil and gas field, by which lost circulation, a severe problem occurred previously when drilling into fractured reservoir beds, was controlled, thereby minimizing formation damage. The $\mathrm{O} / \mathrm{W}$ emulsion drilling fluid was prepared by adding $20 \%$ (by volume) No. 5 mineral oil (with high flash point, as dispersed phase) into seawater (as continuous phase). Surfactant HTO-1 (as a primary emulsifier) and non-ionic surfactant HTO-2 (as a secondary emulsifier) were added into the drilling fluid system to stabilize the emulsion; and YJD polymer was also added to seawater to improve the viscosity of the continuous phase (seawater). The drilling fluid was characterized by high flash point, good thermal stability and high stability to crude oil contamination.
\end{abstract}

Key words: Oil-in-water emulsion drilling fluids, solids-free drilling fluids, lost circulation, depleted reservoir, fractured reservoir

\section{Introduction}

The Bozhong oil and gas field is a maturing offshore oilfield located in the Bohai Bay. It was discovered in 1980 and put into production in May, 1989. Two types of reservoirs were developed in the oil and gas field: porous reservoirs developed in glutenite in the Shahejie Formation, and porous fractured reservoirs developed in Ordovician-Cambrian carbonate. In the porous fractured reservoirs, fractures were well-developed and usually connected with each other, with a general width of 0.1-0.5 mm (there also existed some macro fractures of a width of $0.5-5 \mathrm{~mm})$. These fractures were filled partially with calcite, siliceous and argillaceous cements. Moreover, dissolution pores were developed because the buried hill carbonate reservoirs had undergone long geological weathering and dissolution. On the other hand, the formation pore pressure gradient was reduced to 1 $\mathrm{MPa} / 10 \mathrm{~m}$ after a long period of production. Drilling fluids would easily leak off into the formation during drilling a new well in this type of low-pressure and depleted reservoir. The redevelopment of this type of reservoir calls for low-density drilling fluids. Oil-in-water $(\mathrm{O} / \mathrm{W})$ emulsion drilling fluid is one type of low density drilling fluid and widely used during drilling wells in low-pressure and depleted reservoirs (Chai

\footnotetext{
* Corresponding author. Email: yueqs@sohu.com

Received July 2, 2007
}

et al, 2002; Geng et al, 2001; Qian et al, 2001; Zhang et al, 2002b; Zuo et al, 1996). Considering that the adjustment wells would be drilled in offshore depleted reservoirs, near balanced drilling would be applied and seawater was used as the continuous phase when preparing $\mathrm{O} / \mathrm{W}$ emulsion drilling fluids.

\section{Fluid formulation}

\subsection{Emulsifiers}

An $\mathrm{O} / \mathrm{W}$ emulsion drilling fluid is an unstable thermodynamic system, formed by two immiscible fluids, water and oil. Emulsifiers are usually used to stabilize emulsions by reducing interfacial tension of the system. Selecting emulsifiers is the key to a stable emulsion drilling system (Ma et al, 2006; Liu et al, 2006; Yan et al, 1993; Yan and Wang, 2004; Zhang et al, 2002a).

Based on the emulsion theory, emulsifiers with a HLB value of 8-18 may be preferred to stabilize an $\mathrm{O} / \mathrm{W}$ emulsion. Table 1 indicates that emulsions containing composite emulsifiers were more stable than those containing a sole emulsifier, because the composite emulsifiers could form a higher-intensity interfacial film at the oil-water interface, which is more durable and is beneficial to emulsion stabilization. In this study, a cationic surfactant HTO-1 was used as a primary emulsifier, and a non-ionic surfactant HTO-2 as a secondary emulsifier. 
Table 1 Stability of O/W emulsions containing different emulsifiers

\begin{tabular}{ccc}
\hline Emulsifier & Concentration, \% & Stability \\
\hline HTO-1 & 1.0 & Instable \\
HTO-2 & 1.0 & Instable \\
OP-10 & 1.0 & Instable \\
ABS & 1.0 & Instable \\
AES & 1.0 & Instable \\
Sodium oleate & 1.0 & Instable \\
HTO-1+HTO-2 & $1.0+0.4$ & Stable \\
\hline
\end{tabular}

\subsection{Viscosifer}

Beside emulsifiers, the viscosity of continuous phase (seawater in this study) is one of the main factors influencing $\mathrm{O} / \mathrm{W}$ emulsion stability. Nine polymers were added to seawater to improve its viscosity respectively, and their rheological behavior is shown in Table 2. After comprehensive consideration of polymer price and rheological behavior of polymer solution, YJD was used as viscosifier.

\subsection{Formulation}

According to the principle of near balanced drilling, the density of $\mathrm{O} / \mathrm{W}$ drilling fluid system was determined to be in the range of $0.96-1.02 \mathrm{~g} / \mathrm{cm}^{3}$, thus its volumetric ratio of seawater to No. 5 mineral oil was 80:20.

Based on the results of laboratory experiments, a solidsfree $\mathrm{O} / \mathrm{W}$ drilling fluid was developed, and Table 3 gives its formulation.

Table 2 Viscosifying action of different polymers in seawater

\begin{tabular}{|c|c|c|c|c|c|c|}
\hline Polymer & $\begin{array}{c}\text { Concentration } \\
\% \\
\end{array}$ & $\begin{array}{l}\text { Temperature } \\
{ }^{\circ} \mathrm{C} \\
\end{array}$ & $\begin{array}{c}\text { Apparent viscosity (AV) } \\
\mathrm{mPa} \cdot \mathrm{s}\end{array}$ & $\begin{array}{l}\text { Plastic viscosity (PV) } \\
\mathrm{mPa} \cdot \mathrm{s}\end{array}$ & $\begin{array}{c}\text { Yield point (YP) } \\
\mathrm{Pa} \\
\end{array}$ & $\begin{array}{c}\mathrm{YP} / \mathrm{PV} \\
\mathrm{s}^{-1}\end{array}$ \\
\hline HEC & 0.8 & 22 & 34.0 & 24.0 & 10.0 & 0.42 \\
\hline HV-PAC & 0.8 & 22 & 46.5 & 22.0 & 24.5 & 1.11 \\
\hline HV-CMC & 0.8 & 22 & 35.0 & 19.0 & 16.0 & 0.84 \\
\hline 80A51 & 0.8 & 22 & 12.5 & 11.0 & 1.5 & 0.14 \\
\hline KPAM & 0.8 & 22 & 8.5 & 8.0 & 0.5 & 0.06 \\
\hline Flowzen & 0.8 & 30 & 32.5 & 10.0 & 22.5 & 2.25 \\
\hline Sesbania & 1.0 & 30 & 20.5 & 13.0 & 7.5 & 0.58 \\
\hline YJD & 0.3 & 30 & 10.5 & 6 & 4.5 & 0.75 \\
\hline $\mathrm{XC}$ & 0.3 & 30 & 10 & 5 & 5 & 1.0 \\
\hline
\end{tabular}

Table 3 Typical formulation of O/W drilling fluid

\begin{tabular}{ccc}
\hline Additive & Composition, \% & Function \\
\hline YJD polymer & 0.6 & Viscosifier \\
HTO-1 & 1.0 & Primary emulsifier \\
HTO-2 & 0.4 & Secondary emulsifier \\
PAC & 0.4 & - \\
Modified starch fluid & 0.6 & Fluid loss control \\
NaOH & 0.2 & - \\
\hline
\end{tabular}

Preparation method: YJD polymer and $\mathrm{NaOH}$ were dissolved in seawater, and then a polymeric colloid was obtained. The mineral oil was mixed with emulsifiers, the mixture was then put into the pre-prepared polymeric colloid. After blending for $30 \mathrm{~min}$, the resulting slurry obtained was an $\mathrm{O} / \mathrm{W}$ emulsion drilling fluid.

\section{Evaluation of $\mathrm{O} / \mathrm{W}$ emulsion drilling fluid}

\subsection{Stability}

The stability of $\mathrm{O} / \mathrm{W}$ emulsion drilling fluids was evaluated by measuring the water separated from the system after centrifugal separation (Cambiella et al, 2007; Chen and Han, 2000; Fan et al, 2007; Kang and Sun, 2006; Tong et al, 
2006). In centrifugal separation, the less the water separates, the more stable the system is. After aging for 120 or $240 \mathrm{~h}$ at room temperature, the prepared $\mathrm{O} / \mathrm{W}$ emulsion drilling fluid was centrifuged for 5 or $10 \mathrm{~min}$ at 3,000 r/min, then any water separated from the emulsion drilling fluids was measured. Data in Table 4 indicate that the $\mathrm{O} / \mathrm{W}$ drilling fluid prepared with the formulation stated above is stable.

\subsection{Temperature-resistant properties}

After aging for $16 \mathrm{~h}$ at different temperatures, the properties of $\mathrm{O} / \mathrm{W}$ emulsion drilling fluids were measured, and test results are shown in Table 5. It could be seen that after aging at $60-110^{\circ} \mathrm{C}$, the typical properties of the system changed slightly, with a decrease in viscosity and yield point, and an increase in fluid loss. However, creaming

Table 4 Centrifugal test of $\mathrm{O} / \mathrm{W}$ emulsion drilling fluid after aging a specific time

\begin{tabular}{ccccc}
\hline Oil-water volumetric ratio & $\begin{array}{c}\text { Aging time } \\
\mathrm{h}\end{array}$ & $\begin{array}{c}\text { Centrifuging time } \\
\min \end{array}$ & $\begin{array}{c}\text { Water separated } \\
\mathrm{ml}\end{array}$ & Stability \\
\hline $80: 20$ & 120 & 5 & 0 & Stable \\
$80: 20$ & 240 & 10 & 0.05 & Stable \\
\hline
\end{tabular}

Table 5 Typical properties of O/W emulsion drilling fluid after aging at different temperatures

\begin{tabular}{|c|c|c|c|c|c|c|c|}
\hline $\begin{array}{l}\text { Aging temperature } \\
{ }^{\circ} \mathrm{C}\end{array}$ & Aging & $\begin{array}{l}\text { Apparent viscosity } \\
\mathrm{mPa} \cdot \mathrm{s}\end{array}$ & $\begin{array}{l}\text { Plastic viscosity } \\
\mathrm{mPa} \cdot \mathrm{s}\end{array}$ & $\begin{array}{l}\text { Yield point } \\
\mathrm{Pa}\end{array}$ & $\phi 6 / \phi 3$ & $\begin{array}{l}\text { API Filter } \\
\text { loss } \\
\mathrm{ml}\end{array}$ & $\begin{array}{c}\text { HTHP Filter } \\
\text { loss } \\
\mathrm{ml}\end{array}$ \\
\hline Room temp. & Pre-rolling & 23.5 & 13 & 10.5 & $3 / 2$ & 3.5 & - \\
\hline 60 & Post-rolling & 22.0 & 14 & 8.0 & $1 / 0$ & 3.5 & 8 \\
\hline 80 & Post-rolling & 21.0 & 13 & 8.0 & $3 / 2$ & 3.5 & 9 \\
\hline 100 & Post-rolling & 19.5 & 12 & 7.5 & $3 / 2$ & 4.0 & 12 \\
\hline 110 & Post-rolling & 18.0 & 11 & 7.0 & $3 / 2$ & 4.5 & 15 \\
\hline 120 & Post-rolling & \multicolumn{6}{|c|}{ Creaming occurred and more water separated } \\
\hline
\end{tabular}

Notes: Hot rolling time was $16 \mathrm{~h}$

occurred when the drilling fluid was aged at $120{ }^{\circ} \mathrm{C}$. The formation temperature of the Bozhong reservoir was about $110{ }^{\circ} \mathrm{C}$, therefore the drilling fluids developed can meet the requirements of drilling operations.

\subsection{The stability of drilling fluids to crude oil contamination}

Crude oil may flow into wellbore and mix with drilling fluids during near balanced drilling, thus the compatibility of drilling fluid with crude oil is very important. So, model contamination experiments (artificial contamination with crude oil) were carried out with the results given in Figs.1, 2 and 3 .

Figs. 1 through 3 show the influence of crude oil concentration on rheological behavior, filter loss and density of the $\mathrm{O} / \mathrm{W}$ emulsion drilling fluid. As shown, as crude oil contamination increased, the apparent viscosity, plastic viscosity and yield point of the system increased significantly before rolling. After rolling, the apparent viscosity and yield point of the system decreased when crude oil concentration was the same, but the plastic viscosity increased. The reason is that some crude oil is emulsified well after rolling, and the number of emulsion droplets is increased. With the increase of crude oil invasion, the HPHT filter loss and API filter loss changed slightly, but the density of the system decreased gradually. When mixed with $50 \%$ crude oil, the $\mathrm{O} / \mathrm{W}$ drilling fluid still can satisfy the requirements of drilling operation. It could be seen that the drilling fluid prepared exhibited high stability when exposed to $50 \%$ oil contamination. 


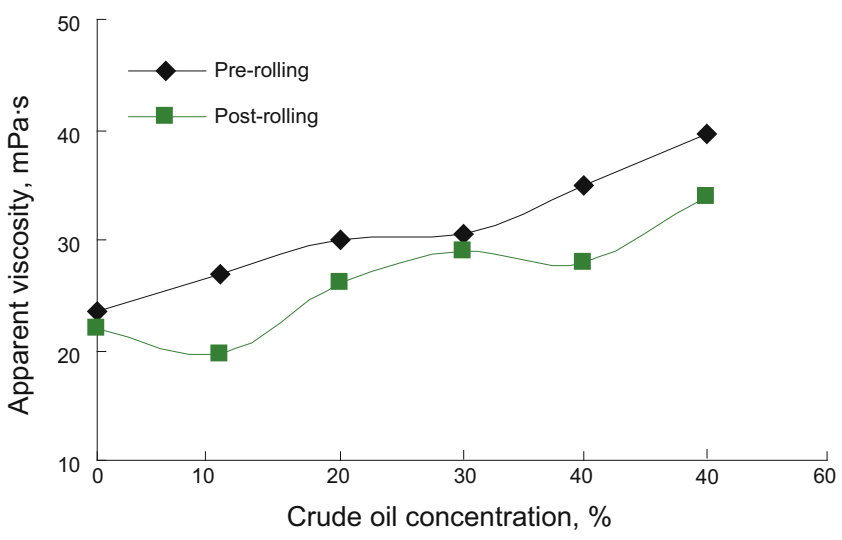

(a) Apparent viscosity

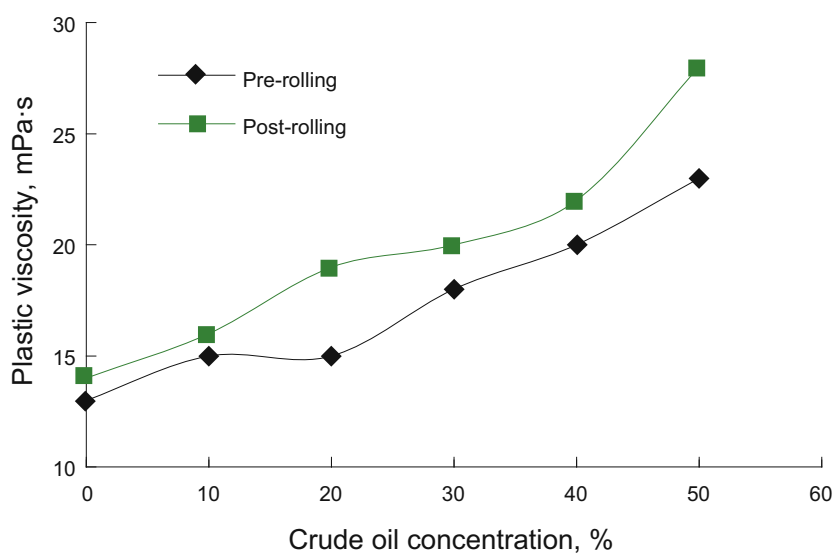

(b) Plastic viscosity

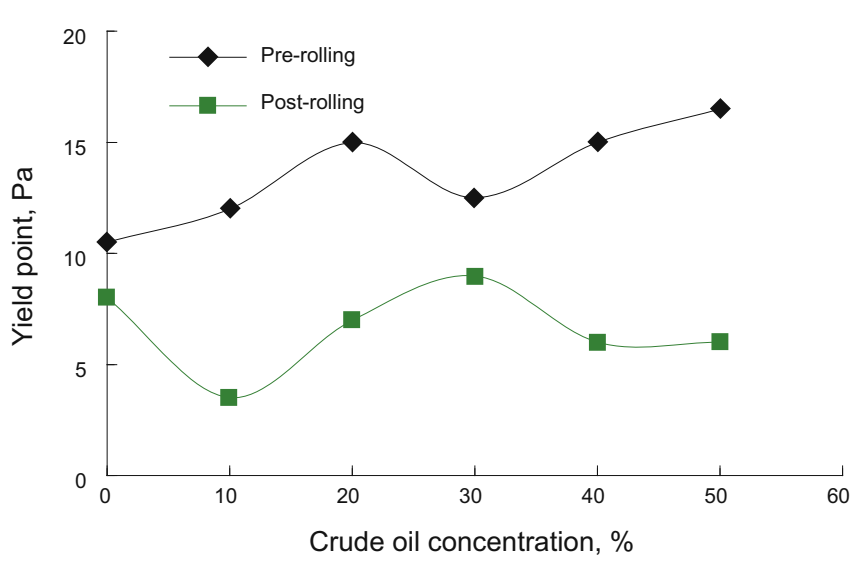

(c) Yield point

Fig. 1 Influence of oil concentration on the rheological behavior of $\mathrm{O} / \mathrm{W}$ emulsion drilling fluid (Hot rolling conditions: $80^{\circ} \mathrm{C}, 16 \mathrm{~h}$ )

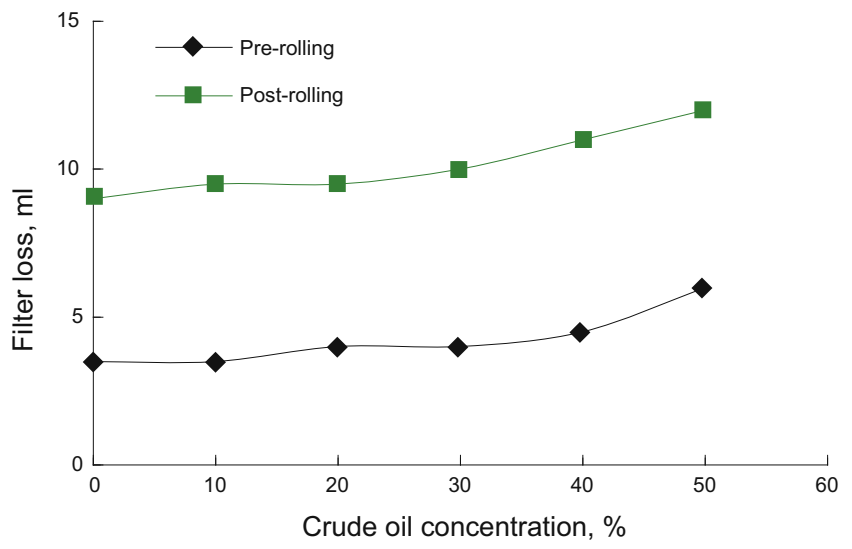

Fig. 2 Influence of oil concentration on the fluid loss of $\mathrm{O} / \mathrm{W}$ emulsion drilling fluid

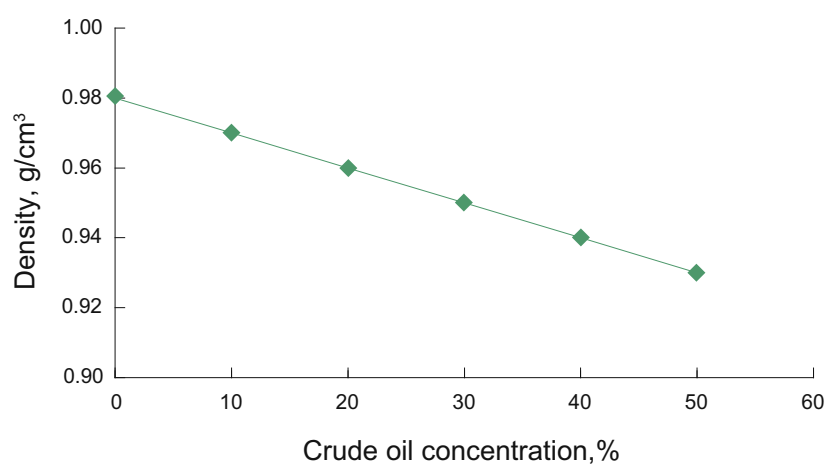

Fig. 3 Influence of oil concentration on the density of $\mathrm{O} / \mathrm{W}$ emulsion drilling fluid

\subsection{Safety}

During near balanced drilling, crude oil can rush into the borehole and mix with the $\mathrm{O} / \mathrm{W}$ emulsion drilling fluid in the event of a pressure surge or pump shutdown. The flash point of the drilling fluids mixed with different volumes of crude oil was measured to investigate the influence of crude oil concentration on application safety of the fluid system, with experimental results shown in Table 6 .

The experimental results show that the $\mathrm{O} / \mathrm{W}$ emulsion drilling fluid itself had a very high flash point, and the flash point changed slightly after mixing with different volumes $(10 \%-50 \%)$ of crude oil. This indicates that the invaded oil was dispersed in water, the continuous phase. Therefore, it can be anticipated that this drilling fluid is safe not only in laboratory but also during drilling operations, and that the drilling fluid had high stability at a wider range of oil-water ratio.

Table 6 Influence of crude oil invasion on the flash point of $\mathrm{O} / \mathrm{W}$ emulsion drilling fluid system

\begin{tabular}{ccccccc}
\hline Oil concentration, $\%$ & 0 & 10 & 20 & 30 & 40 & 50 \\
\hline Flash point, ${ }^{\circ} \mathrm{C}$ & $>100$ & $\begin{array}{c}100^{\circ} \mathrm{C} \text { boiling } \\
\text { without flashing }\end{array}$ & $\begin{array}{c}100^{\circ} \mathrm{C} \text { boiling } \\
\text { without flashing }\end{array}$ & $\begin{array}{c}100^{\circ} \mathrm{C} \text { boiling } \\
\text { without flashing }\end{array}$ & $\begin{array}{c}100^{\circ} \mathrm{C} \text { boiling } \\
\text { and burning }\end{array}$ & $\begin{array}{c}100^{\circ} \mathrm{C} \text { boiling } \\
\text { and burning }\end{array}$ \\
\hline
\end{tabular}




\section{Field case}

Since fractures were well-developed in the depleted buried hill reservoirs in the Bozhong 28-1 oil and gas field, an undesirable loss of drilling and completion fluids into the surrounding formation occurred when drilling or completing with conventional drilling and completion fluids. For example, over $2,000 \mathrm{~m}^{3}$ of conventional drilling fluids flowed into the formation when Well N3 and Well N5 penetrated the fractured buried hill reservoir bed; and over 7,900 $\mathrm{m}^{3}$ of seawater flowed into the formation during workover operations of Well N4.

The $\mathrm{O} / \mathrm{W}$ emulsion drilling fluid was successfully used in Well N8 drilled in the depleted reservoir in the Bozhong 28-1 oil and gas field. Well N8 was drilled with the O/W drilling system in the interval from $3,520.05$ to $3,784 \mathrm{~m}$. The typical properties of the $\mathrm{O} / \mathrm{W}$ emulsion drilling fluids at various well intervals of this well are presented in Table 7. The results of field application indicate that the performance of the $\mathrm{O} / \mathrm{W}$ emulsion drilling fluid was stable and the drilling fluid invasion into the depleted formations was effectively controlled, thereby ensuring safe and smooth drilling operations. Drilling fluids and cuttings were recovered after drilling, therefore the pollution of marine environment caused by drilling for oil and gas was reduced and controlled.

Following the successful application in Well N8, Well N3 was drilled by using the $\mathrm{O} / \mathrm{W}$ drilling system and optimized operation parameters. During drilling, no overflow and lost circulation occurred. Flowing production rates of wells N8 and $\mathrm{S} 3$ are listed in Table 8.

Table 7 Typical properties of the O/W emulsion drilling fluids used in Well N8

\begin{tabular}{|c|c|c|c|c|c|c|}
\hline $\begin{array}{c}\text { Depth } \\
\text { m }\end{array}$ & $\begin{array}{l}\text { Density } \\
\mathrm{g} / \mathrm{cm}^{3}\end{array}$ & $\begin{array}{c}\text { Funnel viscosity } \\
\mathrm{s}\end{array}$ & $\begin{array}{c}\text { Plastic viscosity } \\
\mathrm{mPa} \cdot \mathrm{s}\end{array}$ & $\begin{array}{c}\text { Yield point } \\
\mathrm{Pa}\end{array}$ & $\begin{array}{l}\text { Gel strength } \\
\mathrm{Pa} / \mathrm{Pa}\end{array}$ & $\begin{array}{l}\text { API filter loss } \\
\mathrm{ml}\end{array}$ \\
\hline 3520.05 & 0.96 & 50 & 13 & 11 & - & 4.8 \\
\hline 3523.6 & 0.96 & 51 & 14 & 12 & $5 / 3$ & 5.0 \\
\hline 3531 & 0.99 & 42 & 12 & 11 & $5 / 6$ & 4.2 \\
\hline 3571 & 0.99 & 43 & 10 & 13 & $4 / 6$ & 4.0 \\
\hline 3582 & 0.99 & 46 & 14 & 14 & $5 / 6$ & 4.0 \\
\hline 3636 & 1.00 & 45 & 13 & 14 & $5 / 6$ & 3.4 \\
\hline 3643 & 1.00 & 45 & 13 & 14 & $5 / 7$ & 3.4 \\
\hline 3699 & 1.00 & 43 & 13.92 & 14 & $5 / 6$ & 3.2 \\
\hline 3702 & 1.00 & 44 & 12 & 15 & $5 / 6$ & 3.4 \\
\hline 3758 & 1.00 & 45 & 12 & 14 & $5 / 6$ & 3.4 \\
\hline 3767 & 1.00 & 45 & 13 & 14 & $5 / 6$ & 3.2 \\
\hline 3783 & 1.00 & 45 & 12 & 15 & $5 / 6$ & 3.2 \\
\hline TD 3784 & 1.02 & 44 & 13 & 14 & $5 / 6$ & 3.6 \\
\hline TD 3784 & 1.05 & 46 & 12 & 15 & $5 / 6$ & 3.6 \\
\hline
\end{tabular}

Table 8 Flowing production of Well N8 and Well S3

\begin{tabular}{ccccccc}
\hline Well & $\begin{array}{c}\text { Bean } \\
\mathrm{mm}\end{array}$ & $\begin{array}{c}\text { Oil pressure } \\
\mathrm{psi}\end{array}$ & $\begin{array}{c}\text { Casing pressure } \\
\mathrm{psi}\end{array}$ & $\begin{array}{c}\text { Gas production } \\
10^{4} \mathrm{~m}^{3} / \mathrm{d}\end{array}$ & $\begin{array}{c}\text { Liquid production } \\
\mathrm{m}^{3} / \mathrm{d}\end{array}$ & $\begin{array}{c}\text { Water cut } \\
\%\end{array}$ \\
\hline $\mathrm{N} 8$ & 13 & 2700 & 0 & 15.92 & 58.32 & 7 \\
$\mathrm{~S} 3$ & 15.87 & 2220 & 0 & 45.38 & 115.2 & 0 \\
\hline
\end{tabular}




\section{Conclusions}

1) A solids-free oil-in-water $(\mathrm{O} / \mathrm{W})$ emulsion drilling fluid system was developed in this study. The designed drilling fluid system was an excellent drilling system for depleted fractured reservoir beds in the Bozhong 28-1 oil and gas field. The system exhibits favorable rheological behavior and filtration control characteristics, which could reduce lost circulation of drilling fluid in fractured formations, thereby formation damage.

2) The $\mathrm{O} / \mathrm{W}$ emulsion drilling fluids had high flash point, good stability and high stability to temperature and crude oil contamination.

\section{References}

Cambiella A, Benito J M, Pazos C, et al. Interfacial properties of oilin-water emulsions designed to be used as metalworking fluids. Colloids and Surfaces A: Physicochemical and Engineering Aspects. 2007. 305(15): 112-119

Chai J P, Cheng X H, Lu Z H, et al. Drilling the underbalanced horizontal Well WP-1 using oil-in-water saturated brine system. Drilling Fluid and Completion Fluid. 2002. 19(4): 29-30, 41 (in Chinese)

Chen G D and Han L Y. Experiment notes of emulsification. Journal of Shangrao Teachers College. 2000. 20(3): 46-48 (in Chinese)

Fan Y P, Wang H J and Zhang Q. Microwave demulsificationcentrifugation separation of complicated emulsion in the middle part of a crude tank: Centrifugalization. The Chinese Journal of Process Engineering. 2007. 7(2): 258-262 (in Chinese)

Geng X G, Zheng T and Hao L Z. Application of oil-in-water drilling fluid in drilling of Songshen Well 101. Petroleum Drilling Techniques. 2001. 29(4): 44-45 (in Chinese)
Kang W L and Sun C L. Developments of demulsification methods with oilfield emulsion. Pipeline Technique and Equipment. 2006. (2): 1-4 (in Chinese)

Liu Z M, Zhang A L, Wag F Q, et al. Optimizing screening of anionic/ nonionic mixed emulsifier and preparing high and low temperature resistant oil-in-water drilling fluid. Oilfield Chemistry. 2006. 23(4): 297-300 (in Chinese)

Ma Y, Cui M R and Sun S L. Research and application of oil-in-water drilling fluids system. Fault-block Oil \& Gas Field. 2006. 13(1): 4-6 (in Chinese)

Qian D C, Wang Q, Wang H Tao, et al. Study and application of oilin-water drilling fluid. Drilling Fluid and Completion Fluid. 2001. 18(4): 3-6 (in Chinese)

Tong Z X and Morrow N R. Variations in wetting behavior of mixed-wet cores resulting from probe oil solvency and exposure to synthetic oil-based mud emulsifiers. Journal of Petroleum Science and Engineering. 2006. 52(4):149-160

Yan J N, Menezes J L and Sharma M. Wettability alteration caused by oil-based muds and mud components. SPE Drilling Completion. 1993. 8(1): 35-44

Yan J N and Wang F H. Development and application of the solid emulsifier used to improve the performance of oil-in-water drilling fluid. Petroleum Science. 2004. 1(1): 31-37

Zhang G B, Huang X C, Shi P Q, et al. Study and application statues of low density underbalanced drilling fluid in China. Drilling \& Production Technology. 2002a. 25(6): 74-76 (in Chinese)

Zhang G B, Xu J L, Shi P Q, et al. Application of high temperature and low density oil-in-water drilling fluid in Well Wengu-2. Drilling Fluid and Completion Fluid. 2002b. 19(3): 30-32 (in Chinese)

Zuo F J, Zhang L X, Yang H, et al. Application of low density oil-inwater drilling fluid. Drilling Fluid and Completion Fluid. 1996. 13(5): 35-38 (in Chinese)

(Edited by Sun Yanhua) 